\title{
DECISION SUPPORT FOR CYCLING INFRASTRUCTURE PLANNING: A CASE STUDY IN PŘEROV, CZECHIA
}

\begin{abstract}
Aleš RUDA ${ }^{I}$
DOI: 10.21163/GT_2019.141.10

ABSTRACT:

Speaking about strategical planning, proposing new cycle paths is based on both quantitative evaluating and qualitative respecting strategic intent of the city. The main goal of the paper is to extend currently accepted approaches in modelling of cycling infrastructure towards geostatistical and multicriterial analysis. The research documents a comparative study of different interpolation techniques producing raster surfaces for further processing together with Euclidean distance surface of points of interest. Choosing an appropriate interpolation method, IDW, EBK, RBF, Ordinary Kriging (OK) with spherical variogram, Ordinary Kriging (OK) with linear variogram, Simple Kriging (SK) with spherical variogram and Simple Kriging (SK) with linear variogram) were considered based on state of the art analysis and further examined. EBK and OK (spherical variogram) achieved very similar values bringing the most accurate predicts and small error estimation. Considering two variants (safety and suitability for construction) determining weights, two sets of proposals were presented. Finally, it was find out that none of examined variants itself can be the ideal solution but mixture of both. Using topological overlay missing segments (connections between existing cycle paths) were recommended for new cycle paths construction.
\end{abstract}

Key-words: Cycling, Multicriterial evaluation, Spatial analysis, Strategical planning.

\section{INTRODUCTION}

Building sustainable urban transport has been a matter for several years. With success, cities are improving the environment and increasing the safety of cyclists by creating sustainable urban mobility (Ruda, 2016). This trend is confirmed by the growing importance of the Association of Cyclists in Czechia, the greater participation of cities in the bicycle competition and the improvement of the possibilities of drawing funds from the European funds, the State Fund for Transport Infrastructure. The basic prerequisite for the use of support from subsidy programs is the construction and maintenance of cycling infrastructure, which will increase the safety of transport and its accessibility to persons with reduced mobility. The primary objective of the funding was to eliminate cycling traffic in the extravilan from roads of the 1st, 2nd and 3rd classes and move it into a parallel network of cycle paths (STIF, 2013). The National Cycle Development Strategy (MT and TRC, 2015) accepts the possibility of building cycling lanes and other integration measures in urban areas on roads of the $1^{\text {st }}, 2^{\text {nd }}$ and $3^{\text {rd }}$ classes if the roads meet the width-appropriate parameters, rather than the construction of expensive bicycle paths, because the crossing of the newly built cycling paths increases the danger. The transport policy of the Czech Republic for the period 2014-2020 with a view to 2050 (MT, 2013), where the significance of cyclotourism is mentioned as an important attribute for the development of tourism and

\footnotetext{
${ }^{1}$ Mendel University in Brno, Department of Environmentalistics and Natural Resources, Czech Republic, ales.ruda@mendelu.cz
} 
it does not neglect its importance in commuting to schools and also a concept of ecotourism (Paul, 2013). The National Road Safety Strategy (Besip, 2011) places great emphasis on the support of cyclotourism in connection with the drafting of legislative measures, emphasizes the obligation to use the protective elements in the legislation. In the White Paper on Transport (European Commission, 2011) cyclotourism is addressed in the context of prioritizing transport safety and promoting sustainable behavior. In the Green Book (Commission of the European Communities, 2007) cycling is presented in the context of its importance for environmentally friendly modes of transport and construction of infrastructure aimed at increasing the safety of cyclists, as in the Czech Republic's National Reform Program (2014). In other strategic documents of regional development of the Czech Republic (MPO CR, 2010), Policy of Territorial Development of the CZ (MRD, 2015) and a whole series of resolutions of the Government of the Czech Republic, the significance of cycling is emphasized as a support for improvement of the lifestyle and health of the population.

The aim of the paper is to illustrate the methodology using geostatistical GIS tools and multicriterial analysis and its possible outputs in order to evaluate necessary indicators (according to public authorities) and recommend suitable solution for planning the construction of cycle paths.

\section{LITERATURE REVIEW}

The prediction of cyclist movement is crucial to the planning and allocation of the cost of building a new infrastructure, which is based on the collection of primary data (González and De Lázaro, 2013; Papafragkaki and Photis, 2014). Approaches to the methodology of counting cyclists are addressed in numerous studies (Lindsey et al., 2014; Nordback et al. 2013; Lowry et al., 2013; Schneider et al., 2005; Zaki et al., 2013). Basically, the census can be organized along edges or in nodal points (intersections) of the network in the short or long term (Lowry et al., 2013). Using cyclists' counts as a valuable source of basic data is considered in many studies and various techniques to count bicyclists and pedestrians are described (Nordback et al. 2013). Counts can be conducted at mid-segment or at intersections, short-term or long-term. Nordback et al. (2013) also conclude that counts can either be done manually or by automated technologies. Manual counts are usually binned in time periods of 2 hours, whiles continuous counts 24-hours per day, 365 days per year are gathered by automated counters usually using video counts, active infrared, passive infrared, inductive loops or pneumatic tubes and provide mid-segment screen line. Manual counting is financially less demanding and is usually carried out at irregular moments or continuously 24 hours a day with the support of many bicycle counters. At intersections, bike counting is usually realized manually in short periods of time and uses four different counting techniques: absolute sum of passing cyclists, four-way sum when leaving the intersection, four-way sum on arrival at the intersection, or 12-way sum of arrival and following exit from intersection (Lowry et al., 2013) - the number of paths must be adjusted to the intersection geometry. However, the observed values can be influenced by many factors: weather patterns, demographic characteristics, distance from points of interest etc. (Cardoso et al., 2012; Di Piazza et al., 2011). The accuracy of these results must consider manual counting-related error. Some recent studies (Esawey et al., 2013; Nordback et al., 2013; Nosal 2014; Roll, 2013) combine short-term manual and long-term automatic censuses to achieve the most accurate results. 
However, the original input data obtained from the primary data collection may not be statistically representative; therefore, different statistical prediction methods are used to densify the point field. Straus and Miranda-Moreno (2013) created a spatially regression model that estimates the resulting values at unknown intersections in relation to land use, demographic characteristics, intersection geometry or weather conditions. The least squares linear regression application was used by Griswold et al. (2011) and, similarly to Straus and Miranda-Moreno (2013), a variety of explanatory variables (average slope, presence of cycling markings, land use and traffic characteristics - intersections density, percentage of intersections, etc.). Studies on safety analyses and identification of obstructions in cycling infrastructure (Brüde and Larsson, 1993; Strauss et al., 2015) are also used. To estimate the daily cycling intensity based on short-term traffic surveys, it is appropriate to set a number of different variations in the intensity of cycling: according to the share of the morning intensity between 5:00 am and 9:00 am to all-day (24h) intensity, according to the share of the afternoon intensity between 2:00 pm and 6:00 pm to all-day (24h) intensity, according to both of the above factors and the size and time of the peak intensity (STIF, 2015). With the progressive improvement of tracking technology, global positioning systems can be used for this purpose in combination with GPS tracking devices (Dardanelli et al., 2017; Strauss et al., 2015). In addition to cycling, this data also provides information for assessing the behavior of cyclists (Broach et al., 2012; Donkwook et al., 2014, Xu et al., 2016). In addition to the contribution of quantitative methods of cycling assessment, qualitative studies are equally important. Rybarczyk and Wu (2010) have proposed a model based on the evaluation of supply and demand for cycling infrastructure services. Participatory approach to decision models has also been incorporated (Lundberg and Weber, 2016; Milakis and Athansopoulos, 2014; Shafizadeh and Niemeier, 1997). Application of spatial aspects in the planning process can be found at Evans et al. (2007), who integrated land use (land use) and the characteristics of the transport system to a planning tool Transit Development System, or by Singh et al. (2014) who extended their work with other spatially significant criteria. Modelling a cycling infrastructure load is one of the current challenges which transport infrastructure planning is inherently associated with. A number of studies (Barnes and Krizek, 2005; Cardoso et al., 2012, Nordback et al., 2013, Porter et al., 1999, Turner et al., 1999) show, that neither the prediction of the number of cyclists passing the intersections cannot be generalized. We usually work with not too large data set and even so results with highly accurate estimation are expected. Intersection with passing cyclists represents points with a quantified attribute and two possible solutions are available: estimation of density and interpolation of fictitious (artificial) surface. Creating predictive models of bicycle volumes in urban areas is challenging as it is considered extremely complex issue. But they are widely used for safety analysis and calculation of crash risks, identifying priority locations for facility improvements or estimating changes in volumes following up infrastructure changes and new projects (Griswold et al., 2011). Modelling the load on the territory by cycling is one of the current challenges that transport infrastructure planning is inherently associated with. Many studies (Barnes and Krizek, 2005; Cardoso et al., 2012; Nordback et al., 2013; Porter et al., 1999; Turner et al., 1999) show that neither the prediction of the number of cyclists passing through individual intersections cannot be generalized but we usually have to work with not too large data set, so that modelling must be adapted to the results with high accuracy. Data on passing cyclists through intersections can be primarily represented as points with a quantified attribute, and two processing options are available: estimation of density and interpolation of fictitious (artificial) surface. Density calculation can be solved by the core estimation 
method, with the Kernel Density function (Silverman, 1986) being used in GIS software, resulting in a smoothed surface. If the counting positions are equally distributed and real clusters cannot be considered as random locations suitable for density determination, interpolation is more appropriate. In the context of interpolation methods, the use of local, exact/approximate and stochastic interpolation methods (eg. IDW - Inverse Distance Weighted, RBF - Radial Base Function, Kriging, etc.) has been used, even though some authors have used in their studies global interpolation methods based on the principle of "classical" regression analysis (Griswold et al., 2011; Strauss and Miranda-Moreno, 2013).

\section{RESEARCH METHODOLOGY}

\subsection{Study area}

The city of Přerov is located in the east of the Czech Republic on the river Bečva (Fig. 1). Its geographical location makes it an intersection of ways and heart of Moravia. Nowadays Přerov has approximately 44000 inhabitants and is hospitable place for visitors.

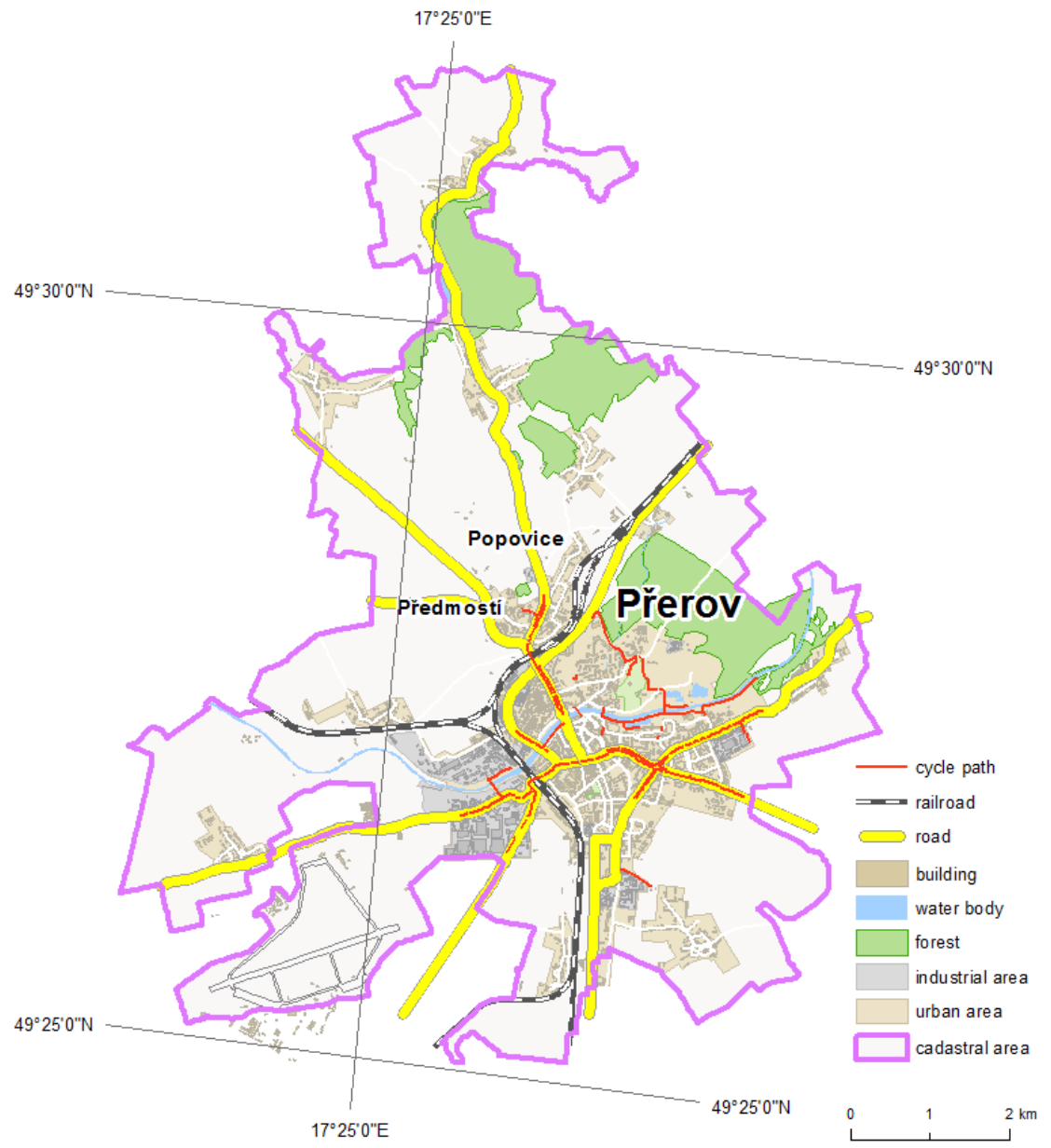

Fig. 1. Cadastral area of Přerov 
Traditional cultural and sport events contribute to the development of tourism as well as comfortable accommodation and broad offer of restaurants and pubs. Currently, Přerov is the social, administrative and cultural centre of the District with developing economics. Cyclotourism is an appropriate mode of transport in Přerov, which is also illustrated by the newly built bicycle tower (storage for bicycles) at the city transport hub (bus and train station). Bicycle moves on marked cycling trails, on cycle paths or out of them. The absence of efficient and complete cycling infrastructure leads to the dispersal of cyclists across the city in an effort to find their safe route. There have been more than $25 \mathrm{~km}$ of cycle paths and cycling lanes in Přerov and its local parts, and more than 20 years have been invested only in the city budget of about 800000 Euros. Support for cycle paths is also stated in the Strategic Plan for Territorial and Economic Development of the Statutory City of Přerov for the period 2014-2020. In addition, a Sustainable Urban Mobility Plan is currently being developed to address transport in a comprehensive manner in line with the needs of residents, city visitors and the business community to improve the quality of city life. With regard to the creation of materials for decision-makers, a methodology including both the collection of primary and secondary data editing, as well as data processing and the interpretation of results was proposed (Fig. 2).

\subsection{Data collection and analysis}

For the case study in the city of Přrov, data was primarily collected at 30 pre-selected counting points (intersections). Bicyclists were counted on two business days during the rush hour in the morning, 5:30 - 9:00 a. m. and in the afternoon, 2:00 - 5:00 p. m. The counting day was set Tuesday (10.5. 2016 and 21.5. 2016) as a business day, that does not precede neither follow the weekend days. The counting occurred twice in two following weeks in May. Volunteer counters marked numbers of arrivals and departures of cyclists in $n$-paths intersections, then partial average numbers were calculated. This way of counting provides not only the total number of cyclists at intersections but also cycling intensity for each direction. Input dataset completion (road and street network) was dealt with data provided by the Municipal Government of city of Prrerov in the scale of 1:10 000 using ArcGIS for Desktop 10.5. Further data processing was realized in S-JTSK Krovak East North coordinate system.

The analysis and data evaluation stage included the identification of the criteria to be assessed. For the purpose of this study, we also considered the surface of the cyclist's estimation of motion, the mapping error of the interpolated surface and the Euclidean distance from the POIs (Points Of Interest). To choose an appropriate interpolation method local, exact/approximate method IDW (Inverse Distance Weighted), RBF (Radial Base Function), Simple Kriging, Ordinary Kriging, Universal Kriging and Empirical Bayesian Kriging were considered based on state of the art analysis as useful and examined. For selecting a suitable interpolation technique, the cross validation was taken into account comparing Mean Error (ME), Root Mean Square Error (RMSE), Root Mean Square Standardized Error (RMSSE) and Average Standard Error (ASE). For interpolation of bicycle movement estimation, data from counting points were used. This data was averaged so that an average number of cyclists per 1 hour during rush hour were calculated. Six methods were tested when choosing the most suitable interpolation method and significant statistical parameters of their results were compared. With regard to the two intended scenarios (traffic safety and suitability for construction), the parameters of the transport network were determined as weight and used in map algebra computation within multicriterial evaluation. 


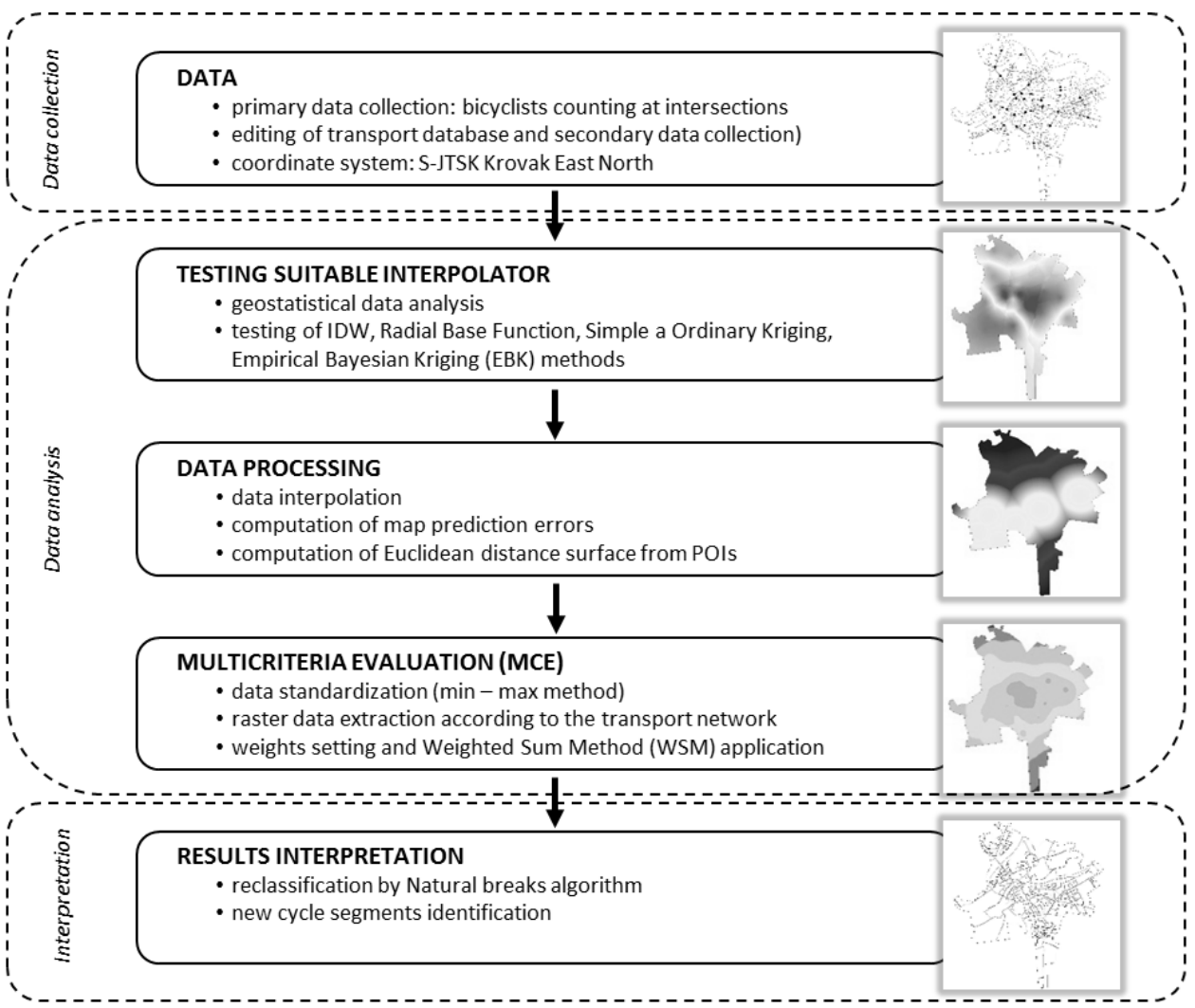

Fig. 2. Methodology flow chart

Data conversion from raster data model to vector data model was also applied. Data standardization was subsequently implemented using the linear range method ( $\min -\max$ ), when the maximizing (1) and minimizing (2) criteria were differentiated using the calculation:

$$
\begin{aligned}
& x_{i j}^{\prime}=\frac{x_{i j}-x_{j}^{\min }}{x_{j}^{\max }-x_{j}^{\min }}, \\
& x_{i j}^{\prime}=\frac{x_{i j}^{\max }-x_{i j}}{x_{j}^{\max }-x_{j}^{\text {min }}},
\end{aligned}
$$

where $x_{i j}{ }^{\prime}$ is the adjusted value for the $i$-th variant of the $j$-th criterion and $x_{i j}$ is the input value.

The adjusted (standardized) value becomes from 0 to 1 . For the two designed scenarios the ranking method was applied to set the weights. The most important criterion is the $k$ number $(k=$ number of criteria), the second $k-1$, the least important criterion refers to 1 . Generally, the $b_{i}$ value is assigned to the $i$-th criterion. The weight of the $j$-th criterion is calculated by (3): 


$$
v_{i}=\frac{b_{i}}{\sum_{i=1}^{k} b_{i}}, \quad \sum_{i=1}^{k} b_{i}=\frac{k(k+1)}{2}
$$

Weighted Sum Method (WSM) was used for calculation of the weighted result within each scenario individually (4).

$$
W S M=v_{i} \sum_{j=1}^{n} b_{j},(4)
$$

where $v_{i}$ represents the $i$-th weight and $b_{i}$ is the standardized value of the $j$-th criterion.

The output surface from MCE calculation was statistically examined and according to data distribution Natural breaks algorithm was used for reclassification into 5 classes representing the range from the less suitable to the most suitable candidates.

\section{RESULTS}

\subsection{Intensity of cyclists' movement}

An ordinary geostatistical data processing necessary for testing interpolation techniques comprises four parts (1. data analysis, 2. structural analysis, 3. applying interpolation technique and 4. evaluation) and is being understood as an iterative procedure, especially between parts 2 - 4). During data analysis basic exploratory statistic data analysis was completed. Relatively diagonal direction with lightly significant deviation in Q-Q plot and together with featureless asymmetry (skewness: 0,35$)$, close mean $(76,1)$ and median $(78,1)$ values localized approximately between minimum $(24,1)$ and maximum $(139,5)$ indicate normal distribution. It was also confirmed by Shapiro-Wilk normality test that the data came from a normally distributed population.

For comparative analysis, seven settings (IDW, EBK, RBF, Ordinary Kriging (OK) with spherical variogram, Ordinary Kriging (OK) with linear variogram, Simple Kriging (SK) with spherical variogram and Simple Kriging (SK) with linear variogram) for data set interpolation have been considered based on the state of the art. Although Universal Kriging (with spherical or linear variogram) is recommended as a useful tool, generated surfaces did not reflect movement of cyclists and this technique has not been applied in the study. Cross-validation was followed in order to compare measured errors and two residues in two farthest points (ID 3 and ID 25; ID means identificator) (Table 1). Two best results in evaluated criteria were typed in bold. The evaluation shows that IDW and RBF have worst results although IDW was the most accurate in prediction of point ID 25 which is caused by computing average values in predicted surface. EBK and OK (spherical variogram) achieved very similar values. Both have smallest ME and ASE is relatively close to RMSE which declares suitable variability of predicted values. These two methods will be compared in detail. Other methods gave satisfactory results but with worse errors than EBK and OK (spherical variogram). Cross-validation results for EBK and OK (spherical variogram) showed that both methods overestimate smaller values and underestimate higher values. The same was determined at both Simple Kriging methods. Opposite EBK, OK (spherical variogram) has regression line closer to theoretically needed diagonal line (see more in Ruda and Floková, 2017). 
Cross-validation results for tested interpolators

Table 1

\begin{tabular}{l|cccccc}
\hline method/error & ME & RMSE & RMSSE & ASE & $\begin{array}{c}\text { ID 3 } \\
\text { residue }\end{array}$ & $\begin{array}{c}\text { ID 25 } \\
\text { residue }\end{array}$ \\
\hline IDW (coefficient $=2)$ & 3.8673 & 32.9553 & - & - & 48.9 & $\mathbf{0 . 0 5}$ \\
RBF (multiquadric) & 2.8621 & 45.7472 & - & - & 48.91 & $\mathbf{- 3 8 . 4}$ \\
EBK & $\mathbf{0 . 7 3 9 5}$ & 32.767 & $\mathbf{0 . 9 6 8 4}$ & $\mathbf{3 3 . 9 8 3 2}$ & -23.72 & 53.69 \\
OK (spherical var.) & $\mathbf{0 . 8 9 4}$ & 32.0088 & $\mathbf{0 . 9 4 8 3}$ & $\mathbf{3 3 . 9 1 8 3}$ & -21.53 & 43.58 \\
OK (linear var.) & 0.9536 & 32.1266 & 0.9475 & 34.0735 & -25.49 & 42.27 \\
SK (spherical var.) & 2.1803 & $\mathbf{3 1 . 8 5 3 6}$ & 0.9095 & 34.5406 & $\mathbf{- 1 9 . 8 8}$ & 46.06 \\
SK (linear var.) & 2.1522 & $\mathbf{3 1 . 2 8 6}$ & 0.9052 & 34.6201 & $\mathbf{- 2 0 . 2 7}$ & 46.39 \\
\hline
\end{tabular}

Deeper analysis of individual variograms and generated prediction surfaces revealed significant differences. Variogram of EBK was set as a result of 100 simulations with standard circular neighborhood type. Its empirical variogram oscillates along theoretical variogram with higher amplitude which can increase the prediction. The EBK prediction map (Fig. 3) estimates higher values in the middle of interpolated area and creates graded zones of smaller values southward from the centre of the city. The surface is relatively smooth and does not estimate enclaves of unexpected values. Farthest areas are estimated without significant changeability. Prediction surface is less smoothed but estimates farthest input points (see ID 3 and ID 25 in Table 1) with higher accuracy. Densest area of input points is realistically graded in order to cyclists' movement. Partial uncertainty of predictions can be seen in southwest corner where values without input points are estimated not quite good for cyclists' movement.

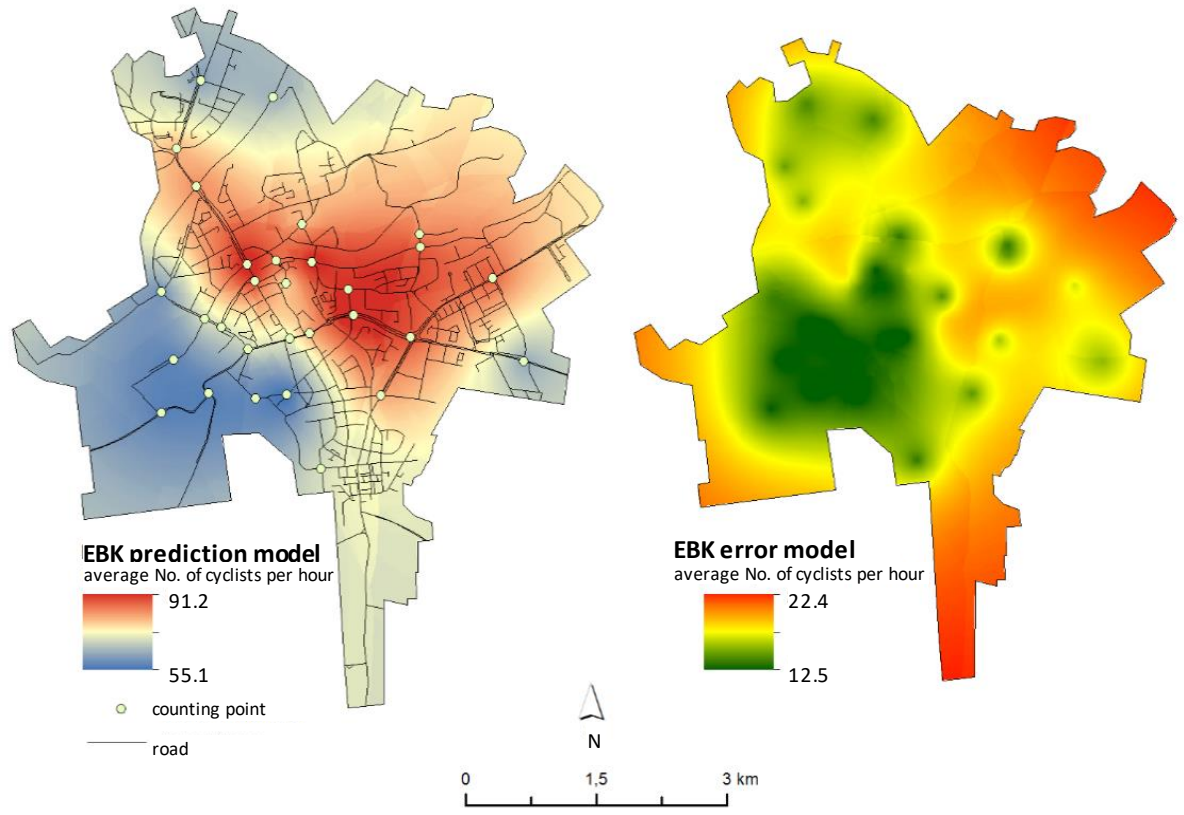

Fig. 3. Prediction map of EBK and map of prediction errors 
Actual model slightly overestimates the variability of estimated values, but provides the most accurate estimate opposite to other interpolators. From the results of the prediction model, it can be seen that the most intense movement of cyclists is estimated in the city centre with a gradual decline towards the east (Meopta's headquarters - the biggest employer) and a slower downward trend to the south (industrial zone). At the northern (the Předmostí suburb area) and the southwestern outskirts (Precheza's - chemical industry and Dalkia's industrial zone), the decline is even more pronounced.

The biggest estimation error is indicated especially in the marginal parts and in the eastern half of the area outside the entry points. The benefit of the error model is to compensate for a higher error estimate, as we can see for example in the southern tip of the territory.

Significant points of interest (POIs) have been chosen with the premise that during days of counting cyclists are heading mostly to work and for services these days: the business centre, bicycle storage, the area of important employers - Dalkia (thermal power plant), Precheza (chemical industry), Meopta (optical industry) and declining Přerov engineering industry. In a simplified form, the surface of the Euclidean distance was calculated from these points to favour those communications that are closer.

\subsection{Multicriterial evaluation}

The suitability of the individual segments was realized using a weighted sum of the standardized values of the above mention criteria (derived surfaces). The calculation was carried out over the pixels above which considered traffic segments pass. Only those communications that could be used for the development of the cycle paths were included $\left(1^{\text {st }}, 2^{\text {nd }}\right.$ and $3^{\text {rd }}$ class roads, roads with cycling parameters, residential connections and nondifferentiated roads).

Pavements with inappropriate parameters, security routes, connections with staircases and roads intensively used for lorry transport were excluded. The type of these communications served to determine the weights for the safety and suitability for construction by the ranking method (Table 2).

Table 2

Weights setting for types of communications

\begin{tabular}{l|cccccc}
\hline & \multicolumn{4}{|c}{ safety variant } & & \multicolumn{1}{c}{$\begin{array}{c}\text { suitability for } \\
\text { construction variant }\end{array}$} \\
\hline criteria & $\boldsymbol{k}$ value & calculation & weight & $\boldsymbol{k}$ value & calculation & weight \\
\hline $1^{\text {st }}$ class road & 1 & $1 / 56$ & 0.02 & 4 & $10 / 35$ & 0.285 \\
$2^{\text {nd }}$ class road & 2 & $3 / 56$ & 0.05 & 4 & $10 / 35$ & 0.285 \\
$3^{\text {rd }}$ class road & 3 & $6 / 56$ & 0.11 & 3 & $6 / 35$ & 0.17 \\
residential connect. & 5 & $15 / 56$ & 0.27 & 1 & $1 / 35$ & 0.03 \\
cycle paths & 6 & $21 / 56$ & 0.37 & 5 & $15 / 35$ & 0.43 \\
nondifferentiated & 4 & $10 / 56$ & 0.18 & 2 & $3 / 35$ & 0.085 \\
\hline
\end{tabular}

The safety variant aims to identify the potential of each segment for the safety of riding, while suitability for construction variant favours segments with inexpensive construction (Fig. 4). 


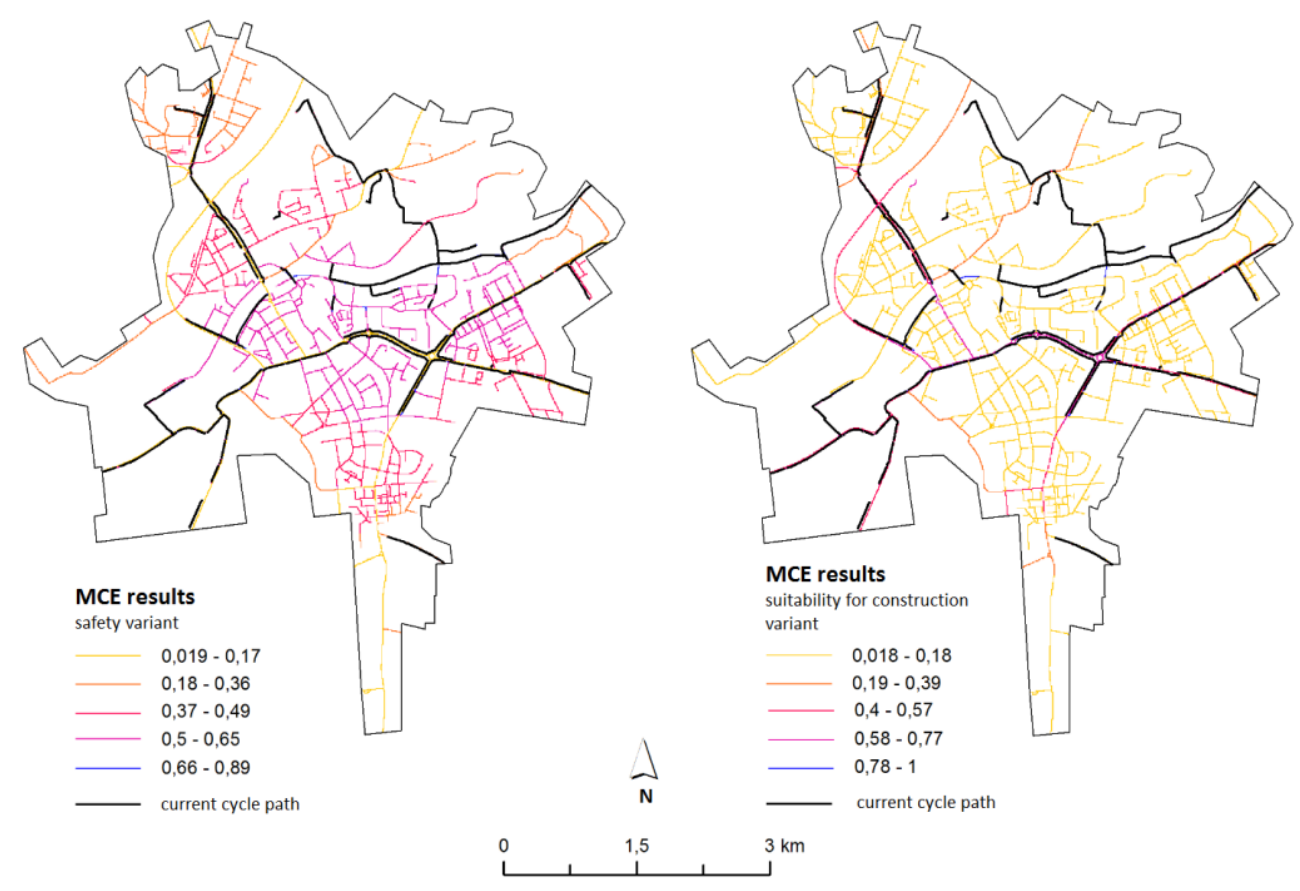

Fig. 4. MCE results.

While the safety variant favours segments of communications that are not used by cars and preserves rather the importance of the cyclists' movement prediction, the suitability for construction variant is based on the assumption that current communications will be also used for cycle path construction.

For comparison, the results of both variants were reclassified by the same algorithm (Fig. 5). At first glance, it is clear that safety variant defines much more moderate sections than suitability for construction variant, which separates the least suitable sections from the most appropriate ones. For the correct interpretation, only segments rated as satisfactory or very satisfying (the last two highest rated categories) were selected for further selection. These segments were identified by a sequence number, and it is clear from the results of both variants that segments $1,3,5$ and 7 were identically identified in both variants.

Another beneficial basis for decision making is also a diagram map representing the number of cyclists arriving at intersections (counting points).

Fig. 6 illustrates the sum of arriving cyclists (during one day) from all examined directions. It is clear from the map, that the busiest parts are already covered by existing cycling infrastructure. In a more detailed perspective, it would be advisable to recommend not only the construction of cycle paths in the segments mentioned above, but also the extension of segments 6,9 and 13 to join the city center, and segments 14-16 which would connect the southern industrial part of the city to the existing cycle network. Only segments $10-11$ should be excluded for now, because they run along the frequented first class road and possible cycle path constructions would include would involve a major extensive reconstruction of the road. 


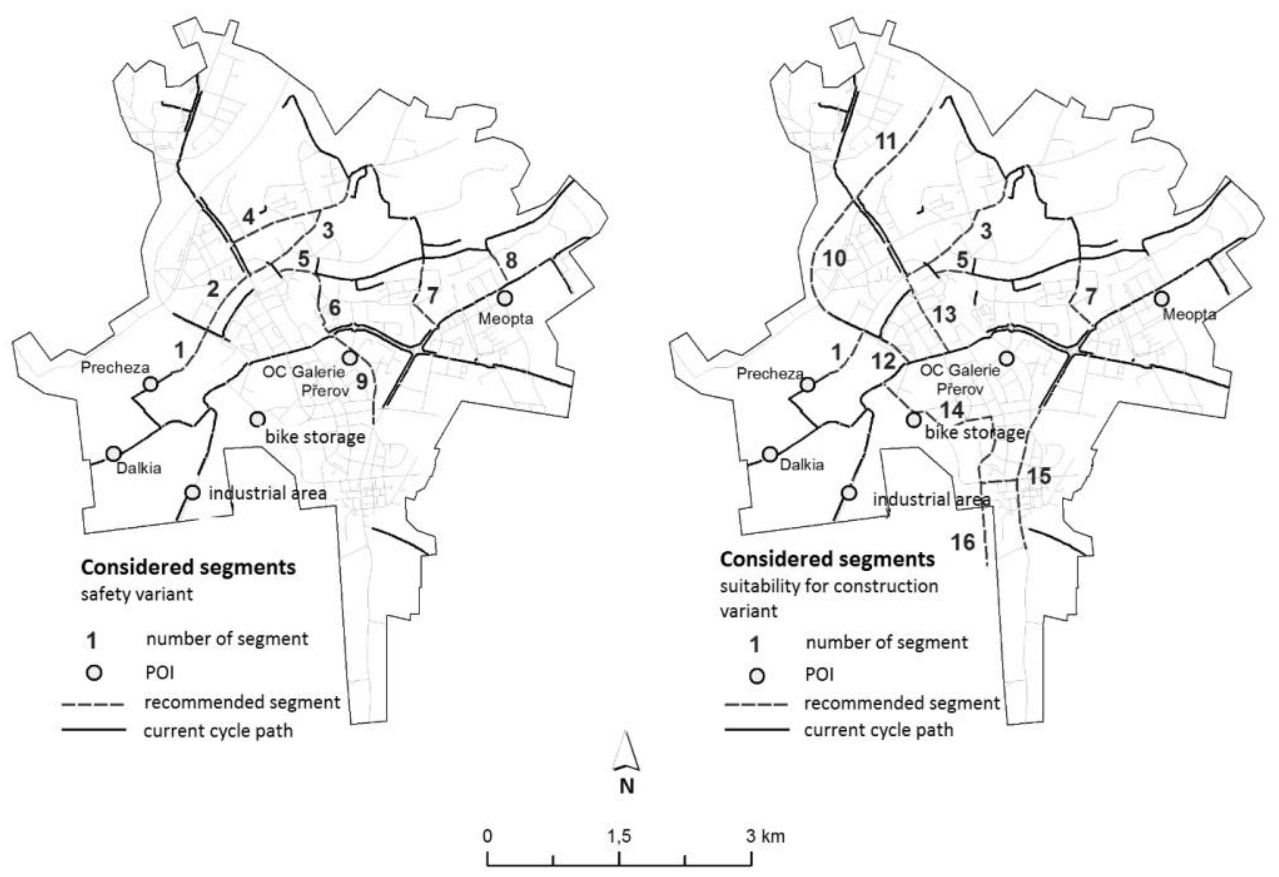

Fig. 5. Recommended segments for cycle path construction.

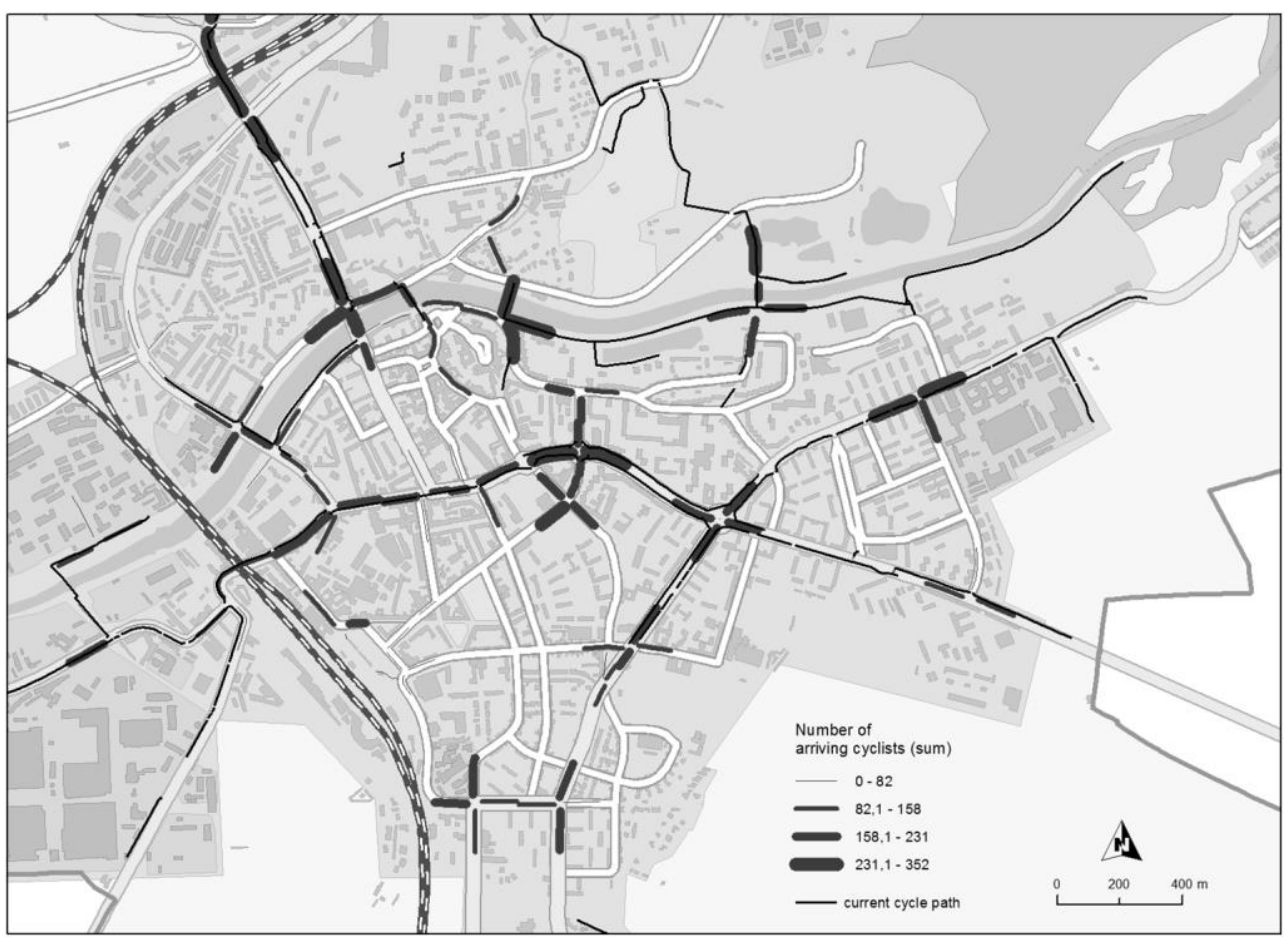

Fig. 6. Loading of intersections by arriving cyclists in the city center. 


\section{CONCLUSIONS}

Predicting cyclist's movement as an example of socioeconomic activity is very difficult but also very challenging task. This kind of activity is associated with attributes describing both the interest of cyclists and the existing infrastructure of cycle paths or any other line transport infrastructure. Counting points providing input data are irregularly distributed with prevailing clusters and vast unmeasured areas. Therefore, estimating needed values is loaded by a high uncertainty. The construction of cycling infrastructure has been solved in Přerov city for a long time. There is no clear unambiguous methodology from the currently available studies. The design of factors, individual criteria and their indicators, including preferences, cannot be determined in advance with regard to the consensual agreement of city representatives. In many ways, it would help to identify the factors that affect the development of cycling. It is also appropriate to involve participatory mapping that takes into account citizens' needs and qualitatively oriented studies that will allow individual preferences to be better evaluated. Spatial decision-making support in GIS will enable decision makers to have a more detailed and visually beneficial view of the solved problem and facilitate work that requires spatial planning and decision making (Gonzáles, M.J. and Pascual M.E., 2016).

The use of the above mentioned methods is very beneficial in relation to the solved problems, but it is also characterized by some degree of uncertainty. The creation of surface of cyclists' movement provides the required information, but does not sufficiently take into account a number of socio-economic characteristics that may affect the movement of cyclists (population deployment, all barrier movements, etc.). The solution could be the use of geographically weighted regression, which both determine the leading factors and consider their impact in the final output. The linear regression model is recommended in applications where precious estimates of average daily traffic are desired, the logistics regression model for applications where level of traffic is desired as it enables predicting the probability of a road belonging to one of traffic volume thresholds. In spite of the fact that non-motorised traffic is influenced by many other factors than motorised there is a matter of correcting generally used methods for non-motorised count. But this approach is data-intensive. Lowry and Dixon (2012) presented own GIS tool to estimate average annual daily traffic based on ordinary least square regression employing functional classification, number of lanes and connectivity importance index as explanatory variables which were found significant for the case study of Moscow, Idaho presented by them. Log linear least square regression was used in the study of the Alameida County, California (Griswold et al., 2011). Dependent variables were transformed using natural logarithm before creating the model. Comparing to negative binomial form of regression model which was also tested in this study similar model coefficient was obtained but log linear form is easier to apply and interpret. Besides bicycle counts there were variables referring to intersection site characteristic (average slope, bicycle lanes and markings), surrounding land use (number and network distance to certain points of interests) and surrounding transportation system (intersection density, connectivity) included in the modelling process.

Another uncertainty lies in the design of individual scenarios, which were built on the priorities of city representatives. Even in this case, it is very important to choose the individual factor scales and to perform a sensitivity analysis at the same time. In both cases, the above-mentioned scenario proposals and the construction of new segments were based on the data from the census (frequency, dominant directions used by cyclists, intersections profile) and the distribution of key points of interest. 
However, it is clear that, with regard to city policy, only one design of suitable segments for the construction of cycling infrastructure cannot be created, but a list of possible solutions, which the city council will subsequently determine or refuse to build, is needed.

\section{R E F E R E N C E S}

Barnes, G. \& Krizek, K. (2005) Estimating Bicycling Demand. Transportation Research Record, Journal of the Transportation Research Board, 1939, 45-51.

Besip. (2011) National Road Safety Strategy 2011-2020. Available from: http://www.ibesip.cz/cz/besip/strategicke-dokumenty/narodni-strategie-bezpecnosti-silnicnihoprovozu/nsbsp-2011-2020 [Accessed September 2018].

Broach, J., Dill, J. \& Gliebe, J. (2012) Where do cyclists ride? A route choice model developer with revealed preference GPS data. Trasportation Research Part A, 46, 1730-1740.

Brüde, U. \& Larsson, J. (1993) Models for Predicting Accidents at Junctions Where Pedestrians and Cyclists are Involved. How Well Do They Fit? Accident Analysis and Prevention, 25 (5), 499509.

Cardoso, O.D., García-Palomares, J.C. \& Gutiérrez, J. (2012) Application of geographically weighted regression to the direct forecasting of transit ridership at station-level. Applied Geography, 34, 548-558.

Dardanelli, G., Marretta, R., Santamaria, A.S., Streva, A., Lo Brutto, M. \& Maltese, A. (2017) Analysis of technical criticalities for GIS modelling an urban noise map. Geographia Technica, $12(2), 41-61$.

Di Piazza, A., Lo Conti, F., Noto, L.V., Viola, F. \& La Loggia, G. (2011) Comparative analysis of different techniques for spatial interpolation of rainfall data to create a serially complete monthly time series of precipitation for Sicily, Italy. International Journal of Applied Earth Observation and Geoinformation, 13 (3), 396-408.

Donkwook, L., Jinsul, K. \& Minsoo, H. (2014) Density Map Visualization for Overlapping Bicycle Trajectories. International Journal of Control and Automation, 7 (3), 327-332.

Esawey, M., Limel, C., Sayed, T. \& Mosa, A.I. (2013) Development of daily adjustment factors for bicycle traffic. Journal Transportation Engeneering, 139 (8), 859-871.

European Commision. (2011) White paper. Available from: https://eur-lex.europa.eu/legalcontent/EN/ALL/?uri=CELEX,52011DC0144 [Accessed September 2018].

Evans IV, J.E., Pratt, R.H., Stryker, A. \& Kuzmyak, J.R. (2007) Transit-Oriented Development -Traveler Response to Transportation System Changes. Transit Cooperative Research Program (TCRP) Report 95. Washington, Transportation Research Board.

Gonzáles, M.J. \& Pascual M.E. (2014) Strategic spatial thinking and change. European Journal of Geography, 7 (1), 24-35.

González, M.J. \& De Lázaro, M.L. (2013) Strategical planning and sustainable development in Spanish cities. European Journal of Geography, 4 (1), 48-63.

Griswold, J.B., Medury, A. \& Schneider, R.J. (2011) Pilot Models for Estimating Bicycle Intersection Volumes. Transportation Research Record, Journal of the Transportation Research Board, 2247 (1), 1-7.

Griswold, J.B., Medury, A. \& Schneider, R.J. (2011) Pilot Models for Estimating Bicycle Intersection Volumes. Available from: http://escholarship.org/uc/item/380855q6

Lindsey, G., Nordback, K. \& Figliozzi, M.A. (2014) Institutionalizing Bicycle and Pedestrian Monitoring Programs in Three States, Progress and Challenges. Available from: http://www.pdx.edu/ibpi/sites/www.pdx.edu.ibpi/files/14-4181_in_Compendium.pdf [Accessed September 2018]. 
Lowry, M. \& Dixon, M. (2012) GIS Tools to Estimate Average Annual Daily Traffic. Available from: http://ntl.bts.gov/lib/45000/45900/45948/KLK725_N12-03.pdf [Accessed September 2018].

Lowry, M., McGrath, R., Cool, S., Cook, R. \& Skiles, M. (2013) Data Collection and Spatial Interpolation of Bicycle and Pedestrian Data. Available from: http://depts.washington.edu/pactrans/wpcontent/uploads/2016/01/UI_KLK853_BikePed_FinalReport_Lowry.pdf [Accessed September 2018].

Ludnberg, B. \& Weber, J. (2016) Non-motorized transport and university populations, an analysis of connectivity and network perceptions. Journal of Transport Geography, 39, 165-178.

Milakis, D. \& Athansopoulos, K. (2014) What about people in cycle network planning? applying participative multicriteria GIS analysis in the case of the Athens metropolitan cycle network. Journal of Transport Geography, 35, 120-129.

Ministry of Industry and Trade (MIT). (2010) Strategic Framework for Sustainable Development of the Czech Republic (Strategický rámec udržitelného rozvoje České republiky). Available from: http://www.mpo.cz/dokument71639.html [Accessed September 2018].

Ministry of Regional Development (MRD). (2015) Territorial Development Policy of the Czech Republic (Politika územniho rozvoje České republiky). Available from: http://www.strukturalnifondy.cz/getmedia/fcf05cb6-a4b9-4af8-ac00-896bfd1b7e32/Politika-uzemniho-rozvojeaktualizace-c-1.pdf?ext=.pdf [Accessed September 2018].

Ministry of Transport (MT), Transport Research Centre (TRC). (2013) Transport Policy of the Czech Republic for the period 2014-2020 with a view to 2050. (Dopravni politika $\check{C} R$ pro obdobi 2014$2020 \mathrm{~s}$ výhledem do roku 2050). Available from: https://www.databazestrategie.cz/cz/md/strategie/dopravni-politika-cr-pro-obdobi-2014-2020-s-vyhledem-do-roku2050 [Accessed September 2018].

Nordback, K., Marshall, W.E. \& Janson, B.N. (2013) Development of Estimation Methodology for Bicycle and Pedestrian Volumes Based on Existing Counts. Available from: http://www.coloradodot.info/programs/research/pdfs [Accessed September 2018].

Nosal, T. (2014) Improving the accuracy of bicycle AADT estimation, temporal patterns, weather and bicycle AADT estimation methods. Available from: http://digitool.library.mcgill.ca/webclient/StreamGate?folder_id=0\&dvs=1472369098397 876\& usePid1=true\&usePid2=true [Accessed September 2018].

Papafragkaki, A. \& Photis, Y.N. (2014) GIS-based location analyses of administrative regions. Applying the median and covering formulations in a comparative evaluation framework. European Journal of Geography, 5 (3), 37-59.

Paul, S. (2013) Analysis of tourism attractiveness using probabilistic travel model, A study on Gangtok and its surroundings. European Journal of Geography, 4 (2), 46-54.

Porter, C., Suhrbier, J. \& Schwartz, W.L. (1999) Forecasting Bicycle and Pedestrian Travel State of the Practise and Research Needs. Transportation Research Record, 1674, 94-101.

Roll, J.F. (2013) Bicycle Traffic Count Factoring, An Examination of National, State and Locally Derived Daily Extrapolation Factors. Available from: http://pdxscholar.library.pdx.edu/open_access_etds/998 [Accessed September 2018].

Ruda, A. \& Floková, L. (2017) Interpolation techniques for predicting the movement of cyclists. In Lecture Notes in Geoinformation and Cartography, eds. Ivan, I., Horák, J. and Inspektor, T., 383-398. Cham, Springer.

Ruda. A. (2016) Exploring tourism possibilities using GIS-based spatial association methods. Geographia Technica, 11 (2), 87-101.

Rybarczyk, G. \& Wu, C. (2010) Bicycle Facility Planning Using GIS and Multi-criteria Decision Analysis. Applied Geography, 30, 282-293. 
Schneider, R., Patten, R. \& Toole, J. (2005) Case Study Analysis of Pedestrian and Bicycle Data Collection in U.S. Communities. Transportation Research Record, Journal of the Transportation Research Board, 1939 (1), 77-90.

Shafizadeh, K. \& Niemeier D. (1997) Bicycle Journey-to-Work Travel Behavior Characteristics and Spatial Attributes. Transportation Research Record, Journal of the Transportation Research Board, 1578, 84-90.

Silverman, B.W. (1986) Density Estimation for Statistics and Data Analysis. New York, Chapman and Hall.

Singh, Y.J., Fard, P., Zuidgeest, M., Brussel, M. \& Van Maarseveen, M. (2014) Measuring transit oriented development, a spatial multi criteria assessment approach for the City Region Arnhem and Nijmegen. Journal of Transport Geography, 35, 130-143.

State Transport Infrastructure Fund (STIF). (2013) Cyklostrategie 2013. Available from: http://www.cyklodoprava.cz/finance/statni-fond-dopravni-infrastruktury [Accessed September 2018].

Strauss, J. \& Miranda-Moreno, L.F. (2013) Spatial Modeling of Bicycle Activity at Signalized Intersections. The Journal of Transport and Land Use, 6 (2), 47-58.

Strauss, J., Miranda-Moreno, L.F. \& Morency, P. (2015) Mapping cyclist activity and injury risk in a network combining smartphone GPS data and bicycle counts. Accident Analysis and Prevention, 83, 132-142.

Turner, S., Hottenstein, A. \& Shunk, G. (1999) Bicycle and pedestrian travel demand forecasting, Literature review. Available from: http://d2dt15nnlpfr0r.cloudfront.net/tti.tamu.edu/documents/1723-1.pdf [Accessed Sept. 2018].

Xu, Y., Shaw, S., Fang, Z. \& Yin, L. (2016 Estimating Potential Demand of Bicycle Tripsfrom Mobile Phone Data-An Anchor-Point Based Approach. ISPRS International Journal of GeoInformation, 5 (8), 131-154.

Zaki, M.H., Sayed, T. \& Cheung, A. (2013) Automated Collection of Cyclist Data Using Computer Vision Techniques. Available from: http://docs.trb.org/prp/13-0745.pdf [Accessed September 2018]. 